\title{
REVIEWING THE MUSEUM - OR: THE COMPLEXITY OF THINGS
}

\section{Walter Grasskamp}

The young historian, Anthony Maloney, Assistant Professor at the McGill University, Montreal, is a specialist on the Victorian era. He spends a few days in California, where, in his motel room on the last weekend before his flight home, he has a dream. Outside his window, on a huge car-park, a complete exhibition on Victorian culture has appeared overnight. The exhibition is a hybrid of world exhibition, museum and annual fair, in which are combined every Victorian object Maloney has ever seen in a museum, with those he has only read about or seen illustrated. Others are virtually unknown to him, but their existence would indeed have been possible.

\section{A MUSEUM DREAM}

Maloney's dream could be the pipe dream of any other historian. He wanders, as though entranced, through the period rooms and galleries, along corridors and past display cabinets, viewing the whole cosmos of period goods before him;

furniture, household utensils, pictures, jewellery, scientific instruments, toys, carpets and hangings, sculpture, handicrafts, patterned wool and fabric, industrial machinery, ceramics, silver, books, furs, clothing for men and women, musical instruments, a powerful telescope on a pedestal, a locomotive, nautical equipment, small weapons, looms, bric-àbrac and curiosities.

In his dream, Maloney realizes that he is in the middle of the greatest exhibition on the Victorian period ever imagined. Every room he enters, every drawer he opens, presents new collections within the collection; photographs, manuscripts, hidden chambers of pleasure, complete libraries, catalogues and stamp collections - the whole cosmos of a period.

Next morning, when he awakes, Maloney raises the blind of the same window. $\mathrm{He}$ is shaken to discover that his dream has not ended. Now, in possession of all his senses, albeit in pyjamas, he wanders the great, many-faceted exhibition again, identifying and dating, straight off, a number of familiar objects; amazed at seeing others, the like of which he could never have dreamed! With routine expertise, he tests as he goes, the authenticity of 
WALTER GRASSKAMP

66 some of the objects, incredulous as to how such artifacts, usually distributed over so many of the most various museums in Britain, have become assembled, overnight, in California.

The dream begins to take on the form of a nightmare, as the media and specialist world demand explanations from the young historian. Two experts of international repute arrive on the scene, and brand their young rival as a fraud. The dean of the faculty cancels his contract. The State of California has the collection assessed to see if it could be claimed as state property, or at least, made liable for tax. The poor director of the Great Victorian Collection is described by the press alternately as a sensation, or as a fraud.

This situation radically changes when a New York public relations agency takes on the despairing scholar, and, within a few hours, has appointed two experts who confirm the significance and fascinating nature of the collection. The collection is professionally invigilated, the publicity work coordinated, scientific research instigated; and public attention inveigled with the plentiful eroticism on hand in the collection. International television teams fly in, and Maloney is informed by his former university in Canada that his over-hasty discharge is to be reconsidered.

Yet the dream still remains a nightmare. Maloney notices that he, like every other devoted collector, has begun to be the prisoner of his possessions. He is tormented by insomnia, at first for fear of what he might dream next. When, however, short fitful sleep comes, he is plagued by an intolerable and feverish vision. A black and white television screen shows continuously the same corridors of his dream museum, through the viewfinder of a surveillance camera.

The plans of his PR agency, in the meantime, follow the lines of a Disneyland-type theme park version of the collection. This, however, fails through lack of cooperation on the part of the unnerved scholar. Instead, a convenient spot near a motorway exit is chosen, and a sort of copy of the Great Victorian Collection established, alongside numerous hotels and retail houses. This has the happy side-effect of keeping the original dream museum largely free of visitors. Many take the motorway replica for the original. I shall not give away the whole plot of the museum story summarised here, but I shall just mention its author, whom I greatly admire. $\mathrm{He}$ is Brian Moore, and his Great Victorian Collection first appeared in 1975.

I decided to use this novel to introduce these reflections, because, as its plot unfolds, a number of questions on museum theory arise, some of which are rather funny, whereas others are just difficult to answer. The one which most interests me is that of the relationship between the museum, the history of collections, and the encyclopaedia. The young Canadian historian's dream represents an ideal museum in as far as every piece needed to illustrate the period is to be found there. The actual situation of museums, of course, is very different. The most intricate fates cast historically connected things to all points of the compass, scattering them, according to political, military, commercial, or other circumstances among the most various museums and collections; whatever a period leaves behind, is instantly displaced not only his- 
torically but also geographically. The Great Victorian Collection in contrast is a museum purged of all historical chance an unimaginable piece of luck for the elucidation of a period.

Such a piece of luck, does, however, provoke the criticism of a long outmoded approach, based on historicism's credo that its perspective presents things as they actually were - a credo to which the Great Victorian Exhibition, in its celebration of detail, appears to submit. That does not detract from the novel's validity. Brian Moore had the wisdom to place the heyday of historicism in a setting that was the epitome of its own illusions. At no other time have museum-like illusions been as intense as they were in the last decades of the nineteenth century. Because Moore weaves contemporaneous world exhibitions into the museum dream, he is able to create a panorama equivalent to this century, of that "exhibitionism" which the nineteenth century handed down, and which Sigmund Freud neglected to analyse.

Historicism, amongst historical philosophies, is surely the most susceptible to the museum-like fetishism of the cult of objects, the reading of things in the framework of their supposed contemporaneity, and bedazzlement by sheer quantity. The authenticity of historical illustration historicism sought, had to resemble the Great Victorian Exhibition. For this fulfils the dream which puts the availability and presence of lost things in an authentic context, the dream which sets out with every attempt at historical visualisation.

Yet, not only the rejoicing in historicism's authenticity permeates the Great Victorian Exhibition. There is another equally modern and formative impulse. It is not just a dream-museum - it is an encyclopaedia as well. Its existence is not the result of the cooperation of countless museums throwing together a travelling exhibition of contemporaneous objects, with the purpose of sending it on tour to whichever venues have happened to take part; no. It is the product of Anthony Maloney's encyclopaedic knowledge of the period, which has materialised overnight in objects. Here too, Brian Moore has caricatured precisely, the century to which his museum satire is dedicated. For the historicist visual euphoria of the 19th century, was, of course, already afflicted by the encyclopaedia.

Here, I have arrived at the core of my topic. The relationship between museum and encyclopedia is the matter to which I devote these observations. I shall finally extend these to consider the possibility of a historical representability of museum history.

\section{MUSEUM AND ENCYCLOPAEDIA}

The museum and the encyclopaedia attained general acceptance in the century of the Enlightenment as models by which to fathom the world, but, they have remained until now, as totally dissimilar from each other as their disposal over material objects. The museum functions through actual objects, while the encyclopaedia filters and distils its subject matter through the media of text and illustration, treating it without material plasticity. Yet, because of this, it is able to manoeuvre more easily into abstract contexts.

In retrospect, one gains the impression that the museum and the encyclopaedia of the 18th century were two competing 
WALTER GRASSKAMP

68 means by which to represent the world, whose prospects differed widely. The museum seemed not only to be dedicated to the past, but soon to be part of it, too. The encyclopaedia, by contrast, appeared as a progressive medium of scientific knowledge and education; as superior to the real museum, by actually making strides, being interdisciplinary, detailed and flexible: already, in fact, a musée imaginaire. Long before André Malraux, inspired by Paul Valéry and Walter Benjamin, had established his own with the agency of photography, the combination of the letterpress and copperplate engraving had already yielded a complete realization of the idea. In consequence the word "museum" was restricted to houses and collections of objects, while before it was open to signify books and magazines, too.

The standing of the encyclopaedia was not damaged by the fact that its material at least from the 18th century onward would usually have been arranged according to the simplest, even apparently banal principle of alphabetical order. This bestowed upon it the reputation of being an organum of a surrealistic world view, resting upon the narrow, arbitrary juxtaposition of a variety of material phenomena. The indifferent alphabetical principle profits from the prompt access it allows to the knowledge accumulated, making the tour of the museum seem, by contrast, a plodding event, or at best, an entertaining one. When we think of Walter Benjamin's famous accusation of cultural history:

The load of cultural treasures heaped upon man's back is increased, but cultural history does not give him the strength to shake it off, to be able to take it in his hands it is the museum one glimpses in the dock, not the encyclopaedia. The simple convenience to the user of the encyclopaedia was a distinctive expression of its efficiency, as the unwieldiness of museum presentation demanded an attitude of contemplation which was threatening to become obsolete.

The question which must be asked, is how did the museum survive the rise of the encyclopaedia, at all? At first, by practising mimesis; the museum parodied the encyclopaedia's triumph, striving itself for encyclopaedic completeness. This was at the expense of the cosmological unity of the art and curiosity cabinets, which had to be relinquished, as the museum was, one might say, arranged into volumes. These were not alphabetically arranged books, as in the case of the encyclopaedia, but special collections divided according to specialist criteria of classification amongst various institutions. This dissolution into specialist collections made possible the encyclopaedic completeness of the museum. Thus the encyclopaedia's triumph was not to be deterred, but the loss of standing for the museum was averted.

This encyclopaediaisation of the museum is not just a reaction to the demands set by the encyclopaedic success, it can ultimately be traced back to the raising of collecting to a scientific pursuit, in the train of the Enlightenment. Previously, collections were made, in which ethnological and antique objects, those of art and of nature, objects of craft and of magic, coexisted. The specialist distinctions and terminology of today were not yet available, or in use. These collections, which betray to the modern viewer a vision of the world which is still quite hazy, were started as art 
or curiosity cabinets, mainly in the 16th and 17 th centuries, and only in the 18th century, arranged and understood according to modern principles. This process claimed for the now appropriate scientific fields, the botanical and zoological pieces, thus divesting them of their mystery, while anthropology and ethnology laid claim on objects of magic and imports from the colonies. Stone collections were recognized as belonging under physical, chemical or geographical definitions. Book collections found their way to libraries. The wax figures which had belonged in curiosity cabinets (like those still in the museums established in the Enlightenment, e. g. in Kassel) were melted down, and their exotic costumes or uniforms of rank were ascribed to ethnology, or military history. Jewellery and fine objects of handicraft were put into museums of art and craft, and prehistorical finds delivered to the auspices of archaeological museums. The social philosopher Max Weber ascertained that the main aim of science was to deliver the world from magic ("Die Entzauberung der Welt"). This was probably never more obvious than in the dissolution of the prescientific collections, and their rearrangement according to their respective new scientific disciplines.

This process of reordering the art cabinets, and those which had housed wonders and curiosities, according to the selection criteria of the scientific disciplines, long remained part of the lesser-noted phases of museum history. This is because the art and curiosity cabinets had been for too long wrongly understood, practically as surrealistic events, instead of, as has in the meantime become accepted, vehicles through which early forms of scientific and technical rationality could be seen at work. The long predominant attitude, which highlighted the strange, the curious, the miraculous and the peculiar, is superseded by a way of seeing which can detect in the impetus of the curiosity cabinets, the ordering impetus of sientific and technical rationality - still tentative, but already on the right path. The curiosity cabinets did not only submit to, but also contributed decidedly to the differentiation of the sciences, and the establishment of their methods. The history and theory of the sciences have mainly underrated the epistemological significance of the early collections. This is possibly an idealistic legacy. Now is high time to examine carefully the obstetrics provided by collecting and museums in the formation of the modern sciences and their disciplines.

When one examines the museum and the encyclopaedia on the lines of a history of representation and classification, as does Michel Foucault in his book Les mots et les choses, their triumph in the 18th century can no longer be taken for granted, as it has been, taking a retrospective view. The path from the cosmological grip of the art and curiosity cabinet to the scientific specialist collections could lead through side and back lanes, and up blind alleys whose prospects might have appeared to contemporaries to be as promising as both the later main trade routes of the spirit, the museum and the encyclopaedia. Consider the Baroque regard for emblematic devices, which propagated a combination of object and language completely different from the encyclopaedia. Think of the still life, which treated material things in a completely different way from the museum (favouring objects, incidentally, which 
WALTER GRASSKAMP

70 could not be collected). What is astonishing in the competition between museum and encyclopaedia, is, perhaps, less that one did not impede the other, but the background of confusion from which they both sprang before assisting the triumph of scientific thought.

The museums were able to assert themselves against the encyclopaedias, burgeoning as they were with the unique nature of the objects in their trust, which defied verbal or illustrative access - their "aura", as Walter Benjamin would have it. The museum objects thus affected were worth seeking out, for a share of this agency. Herein lies the decisive fascination of the modern museum visitor. Unlike the encyclopaedia, it still allows him to deduce motives and constellations, which moulded the unsure and tentative approach to things and words, before bowing down to the rules of science. In its adjustment to the sciences the museum never could, nor wanted to deny the fascination of collecting and hands-on comprehension. For this reason it is a better source of information on the roots of the encyclopaedia than the encyclopaedia itself can be. If the encyclopaedia is an abstraction of knowledge, the museum retains a tenacious grasp upon the specific nature of its topic. It is this obstinacy of the museum against the demands of the age of the encyclopaedia that is overcome by the dream of Brian Moore. His Great Victorian Collection turns out to be an encyclopaedic modernisation of the museum.

\section{HISTORIOGRAPHY}

Of course, the museum survived, mainly because, after the Enlightenment, whose medium was the encyclopaedia, and the triumph of utopianism in the French Revolution, came the 19th century - the century of historicism. In the museum, the bourgeois 19th century discerned a fitting source for the masquerade of image, the nigh-magical place for the euphoric experience of total disposal over all things and epochs, including the noble backdrop of edification, where one might wander, and learn, inside out, without the time and effort of erudition. This guaranteed the museum its survival, but also gave it a historiographic meaning which is still current and seldom reflected. The museum defended historical consciousness as its domain, ordered its chambers with historical lucidity and moulded the sense of historicism - from the history of nature and of the species, all the way to art and its history.

If the role of collections was, perhaps, more significant in the formation and differentiation of the sciences than has previously been acknowledged, the example of the museum was possibly equally meaningful for the historicist image of history, if perhaps, in a rather problematic way. The literary and historical sciences have shown, for nearly twenty years, a growing interest in the question of how the writing of history has changed: how history is constituted in literary historical writing, and how its scientific paradigms have changed in the process. This history of the writing of history has focussed on the literary and scientific representation of history, but not yet, as far as I see, on the museum, which is quite astonishing, because the museum is a, if not the, formative pattern of historical evidence and schematism. For the museum historian, it 
is essential to include this consideration.

The museum propagated an image of history, which, through the tour of the galleries of past ages, tried to reify the linear succession of completed epochs, and the progress of history. This museumimage of history probably emerged in the 17 th century, becoming more apparent in the 18 th century, to be canonised in the 19th. Probably, the art collection, the galleria progressiva served as a paradigm for this. Since then, it has taken on the character of cultural self-evidence, which makes it difficult to see this image of history clearly, as the result itself of a historical process. The museum, particularly the museum of art, has made the resolution and presentation of history in epochs, one giving way to the next, generally so plausible and popular, that it is hard to circumvent the museum-image of history.

Why it might be asked, should one try to circumvent this, the museum's image of history at all? It conveys, ultimately that chronological view of history which was a decisive part of the achievement of the European Enlightenment. The museum decisively accelerated the acceptance of modern thought, particularly in the respect of historiography. Yet there are grounds for mistrusting this image of history. The gravest is that we stand at the end of history, which we undertake to write and to reconstruct, we being also, always the result of that history. One has to be aware of this dependency so as not to become the victim of illusions and ideologies, which, in the course of history, have developed concerning the passing of history - perhaps through accepting at face value the concept of progress. History offers our gaze no authentic experience, but always a previously recounted, and, above all, already interpreted one. As hermeneutics rightly declares, there is no standpoint which we might take, that could be free of the historical mediation that forms our view.

It is therefore worth considering the effect the museum has exercised, since its creation, upon historical thought; whether the fashioning of modern historical thought, and of the museum-like arrangement of objects, were at least parallel developments. Some philosophical and scientific ways of thinking perhaps owed more to previous and contemporaneous museum developments than they admitted then, or betray to us today, especially concerning the notion of an "autonomy" of art. Beat Wyss correctly reconstructs Hegel's aesthetics as his "walk through a museum". The walk through the museum has been chosen as the means by which a guide line could be fixed to judge decline or progress. At any rate, it has also categorized and subordinated to its linear image of history, those cultures which have been supported by other concepts of history. The museum neutralises the historical image of the cultures it integrates. It shows cultures which were carried by a cyclical concept of history, as departments in a museum propagating the linear historical view of development; and of progress. One need not only consider exotic cultures in stressing the contrast in historical images the museums blur. The Medieval Period, with its view of history as an unchanging interim, contrasts with the concept of time adumbrated by the modern museum. The museum department displaying it, "Middle Ages" written above the entrance, is making a contradiction in terms. 


\section{THE MUSEUM AS LABYRINTH}

Such observations might suggest that history should no longer be recounted with the beginning first, letting the end be today. The philosopher Karl Löwith turned his renowned History of Historical Philosophy round and traced his sources backwards. He begins his study with Jacob Burckhardt, and then goes on to Marx and Hegel. Finally via Voltaire, Vico, Joachim of Fiore and Augustine, he comes to the biblical concept of history as acts of God - to which our modern world is more strongly committed than some believers, or even non-believers, may be aware. This approach, in any case, might be criticized as being only a way backwards through the museum, in which the process has merely taken a change of direction.

The true difficulty of the historiographical significance of the museum only becomes apparent when one considers the possible aspect of an appropriate museum history. For here, too, close scrutiny reveals that a museum history would be written according to the museum-model.

From the outset it might, in fact, appear that all that would be necessary would be to trace a clear line of development from the early collections and their presentation, to the proliferation of the museum into the contemporary buildings which form the familiar institution of today. The museum itself is the undoing of the idea of such a historical process. The museum is an architectural and intellectual structural framework of this form of historical perception. It promotes the dilemma of writing the history of an institution which itself represents history, and has therefore propagated a historical image. What histo- rical representation could do the complexity of museum history justice? It would have to be a historical representation that took greater account of the historiographical significance of the museum. For the museum has various histories. It has not only (1) the history of its origination and dissemination, but (2) the history of its survival. These are distinguished by (3) the history of the collected objects inside it. Were this not enough to make the task appear complicated, the true challenge lies in the fact that (4) the museum has become an influential medium in the representation of history, whose forms, of course, have their own history - a meta-history, as it were, of the museum.

Dealing with the complications cited as attending the writing of the history of an institution which itself represents history, is doubtlessly the most difficult, although not the only problem of a multi-layered task. The sequence of rooms poses further traps to thought, which one enters and hardly notices. Thus the museums today present themselves through the subtle diversity of their collections, which appears so plausible and reasonable that many can believe that they have always existed like this. Beside the museum of art there is a history museum, a museum for nature, one for anthropology, and a museum of technology; just to mention the main areas of museum collecting and cultural awareness. Related to these is the richly diversified circle of local and regional museums and specialist collections. The distinction between the different branches of cultural history, also evinced in structural form, between art and nature, technology and magic, appears so plausible as almost to be an innate feature. As it is known, however, 
this impression conceals the recently mentioned restructuring of collections under the dictates of the Enlightenment. It should not be imagined, on the other hand, that this process of re-allocation of objects and new identification of their contexts, happened simultaneously across the board. The discontinuity in the development of the museum, too, makes the historian's task more difficult. At best, the origin, dissemination and revision of the thought which fashioned the collections, may be reconstructed and represented only in ideal types.

There is a further way in which the museum deludes the observer. Constructed for posterity, it signalises the indefinite provision for the objects in its trust, awakening the impression of having been specifically built for its collection. There actually are examples where museums were built to house completed collections, whose hanging was thought out and determined in the minutest detail, at the stage of architectural planning. Today, however, planning a museum for a collection that was already complete would seem a strange idea. In spite of all the theses of decadence current even in the Enlightenment, which saw the museums as the preserve of better, namely, past blossomings of art, the museum is also open for the art of posterity. Thus, changes in hanging have been effected not least because what museum planners might once have regarded as unshakable highpoints in European art, have since found their way into the cellars. The museum's exterior might have remained unchanged, but the landscape of collections has been radically altered by such changes.

Once the dissolution of prescientific contexts in collecting ensued, along the lines of the simultaneously established academic disciplines, the further development of art, which was now liberated, defied any conception that a museum might limit itself to the safekeeping of a collection once made and now complete. The pressure of the advance of art has ensured a historical draught which demands new works in the place of those which have found their way into store, or a moving-up of those on the wall. For other reasons, too, the collections in museums are constantly revised, occasioning the necessity of historiographical distinction between the museum and its collections. A museum does not simply hand down objects. It places them, continually, in different contexts, dissolves collections whose objects are given different relevance, and orders them afresh. To the history of the institution and that of its dissemination, belongs, as a kind of third dimension, a fluctuation of things, released from one-time fixed collections and redeployed, or distributed over a number of different museums, be it in the light of better knowledge, or because accidents of trade or the plunders of war have drawn them along new paths. In this way, certain objects could pass through many institutions before getting to their present place, not necessarily always the best place. As a museum sometimes also recounts the history of its objects, but never that of the collections to which they have belonged, the fluctuation of things during the formative period of museums is faded out. Every attempt to trace the origin of individual objects must surely lead into the labyrinth of an intricate and complex history of collecting and passing down, the 
74 Ariadne's thread of which is not yet woven. One need only follow today's broad and sluggish course of the river of tradition to its countless tributaries, large and small, and their remote sources, to become aware of the heterogeneous elements from which it amalgamated the museum. There can be no museum history in this respect which does not make undue realisations. It is this diversity which has assured the museum the power of intellectual fascination, through all its crises of identity. The survival of the museum may be taken as a warning, perhaps, by all those who, under the constellation of the computer, concede no future for the book. The example of the museum shows that beyond the motivation underlying origins and historically defined functions, media, too, can be guaranteed survival through the flexible deployment of their merits against a background of changing historical conditions.

\section{POSTSCRIPT}

A couple of years ago I was young and foolish enough to believe I had to write a new book on museum history, better than the volume I published in 1981, which has, I am glad to say, run out of print. Only the introduction to this new book was completed, it is the text you have read. It convinced me easily, that my chosen task was not to be mastered, and I dropped it. So, if this text stole half an hour of your life, it saved years of mine, time enough to read novels like Brian Moore's Great Victorian Collection, the message of which of course is: Beware of museums!

\section{NOTE}

The manuscript is translated from German by Heather Eastes.

Walter Grasskamp är professor $i$ konstvetenskap $i$ Aachen. Han har bl a utgivit "Museumsgründer und Museumsstürmer. Zur Sozialgeschichte des Kunstmuseums" (1981), "Der vergessliche Engel" (1986), "Die unbewältigte Moderne. Kunst und Öffentlichkeit" (1989).

Adr: Hauptstrasse 19, D-483 51 EverswinkelAlverskirchen. 